\title{
Process Features of CAST Wastewater Treatment and Its Application in China
}

\author{
Jiaxin Huang ${ }^{1}$, Guori Dong ${ }^{1}$, , Qingwei $\mathrm{Li}^{1}$, Wei Song ${ }^{2}$, Jibin Wang ${ }^{3}$ \\ ${ }^{1}$ School of Resources and Materials, Northeastern University at Qinhuangdao, Qinhuangdao, \\ Hebei, China \\ ${ }^{2}$ Calcium Carbide Factroy of Jilin Petrochemical CO .LTD, Jilin City , Jilin , China \\ ${ }^{3}$ Environmental Management College of China, Qinhuangdao, Hebei, China
}

Keywords: CAST process; development; wastewater treatment; nitrogen and phosphorus removal

\begin{abstract}
CAST, an advanced process of wastewater treatment, has achieved great attention and application. This paper gives an overall introduction on CAST development, principles, features and its current application and research in China. This paper focuses on comparison CAST with SBR, the traditional process, and describes its advantages in details. Then the paper summarizes the current research and the existing problems, lastly, makes a prospect for the future application of CAST process.
\end{abstract}

\section{Instroduction}

Wastewater plays an important role in environment pollution. In various wastewater treatment technologies, sequencing batch reactor (SBR process) is the earliest with advantages of easy construction, stable operation and high removal efficiency and disadvantages of not continuous flow, not suitable for processing large amounts of wastewater and complex management of batch operation. In recent twenty years, with the development of automatic control technology, SBR process has attracted attention and research and a series of new improved process has been developed with some typical SBR deformation process including ICEAS,CASS(CAST), DAT-IAT, UNITANK(Zhou, A.L. \& Niu. Y. J. 2010 ).

CAST process with full title cyclic activated sludge technology, is a new SBR deformation process based on ICEAS and introduces in China at the beginning of 1990s. Through many years of research and practice, it has development into a mature wastewater treatment process. In combination of reaction, precipitation and drainage function, the pollutant is degrading in the whole process of reactor. Microorganism is in the periodic change of aerobic, anoxia and anaerobic. So the reactor realizes pollutants removal, like COD and nitrogen and phosphorus(Zhang,L. \& Wang S.P., et al. 2010). More virtues include good effluent quality, strong adaptability to shock load and good activated sludge, which effectively overcomes problems of sludge expansion, low investment and small occupation area. The high efficiency of CAST process confirms to China's situation and achieves wide promotion. Currently, it has applied into wastewater treatment in industries like domestic wastewater, brewery, pharmacy, chemistry, dyeing, food and butchery(Zou B.H. \& Wang H.B.2012).

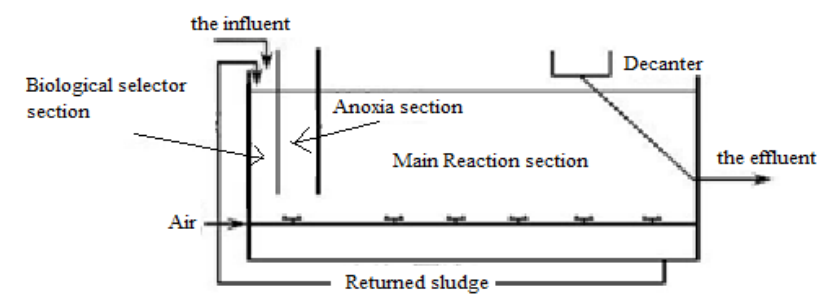

Fig1. CAST reactor structure map 


\section{Principles and process}

Structure map. CAST is composed of three sections (fig.1): biological selector section, pre-reactor section (also anoxia section) and main reaction section with volume ratio at 1:5:30. Some CAST reactor has an agitator in biological selector section and main reaction section to get the uniform mixture of muddy water. There is a sludge return device at the rear part of main reaction section to make sludge return to biological selector section with $20 \%$ of the influent. The decanter is to keep off scum and discharge supernatant (Zhou X.L. et al.2009, Chen K.L. \& Zhan J.2004)

Principle and technical process. The procedure of technical process is divided into four stages: influent period, aeration period, precipitation period and effluent period (and idle period in some literature)(Zhou, A.L. \& Niu. Y. J. 2010 ).

influent period: In CSAT influent period, the influent water first blends with the sludge from last cycle in biological selector section. In this period large substrate concentration gradient is forming from large amount of the influent water. By permease BOD in the influent water is utilized in high concentration sludge. Therefore the good anoxic and anaerobic environments are formed in one cycle and promotes effectively denitrification and anaerobic phosphorus release of PAOs.

Aeration period: In aeration period, activated sludge is fully aerobic carbon removal, aerobic denitrification and aerobic phosphorus excess uptake.

Precipitation period: The wastewater mixture, with no influent water, no aeration and no return sludge, achieves a static environment for flocculation and sedimentation and the separation of mud and water.

Effluent Water period: Supernatant is drained through the floating water decanter. The draining stops when the surface falls to the lowest controlled water level and sludge return starts. The previous cycle is repeated, thus run in cycle .

At least two tanks are required in the CAST system to ensure the continuous feeding in the whole system. In the CAST system with four tanks, continuous water inlet and outlet is achieved through selecting cycle process of each tanks.

A cycle needs about 4-6h. Take the data from Eastern Suburb Wastewater Treatment plant of Huzhou for reference, $0.5 \mathrm{~h}$ of influent, $1.5 \mathrm{~h}$ of aeration, $1.0 \mathrm{~h}$ of precipitation and $1.0 \mathrm{~h}$ of effluent (Chen K.L. \& Zhan J.2004).

\section{CAST process features and advantages}

No sludge bulking. Biological selector section in CAST system effectively keeps off sludge bulking. Biological selector section, a small area at the forepart of reaction tank (10\% of the reactor's general volume), always operates in anoxic and anaerobic environment. The wastewater in reaction tank first touches the return sludge of precipitation period from previous cycle. High concentration substrate promotes mass multiplication of flocs bacteria. The selection of flocculation bacteria as dominant bacteria inhibits the growth of filamentous bacteria. Besides, quick adsorption of activated sludge accelerates the removal of soluble and readily degradable organic matter and restrains the growth of filamentous bacteria. Over multiplication of filamentous bacteria directly leads to sludge bulking. Biological selector section not only speeds up the organic degradation ratio, but also effectively prevents sludge bulking to realize stable operation of the whole system (Bao H.F. \& Li Y.W. et al.2009).

Effective nitrogen and phosphorus removal. Nitrogen removal: Nitrification and denitrification can run simultaneously in CAST process. In addition to denitrification in biological selector section, in main reaction section, through controlling the intensity of oxygen supply and dissolved oxygen concentration of mixture which making it rise from 0 to about $2.5 \mathrm{mg} / \mathrm{L}$, nitrification is operated in aerobic environment around the activated sludge flocs. The transmission of oxygen is limited in activated sludge flocs, while nitrate of high concentration gradient realizes effective denitrification through permeating into the flocs （Zou B.H. \& Wang H.B.2012）.

Phosphorus removal: CAST reaction tank operates alternatively in aeration-non aeration making 
activated sludge in the cycling change of aerobic-anoxic-aerobic, which contributes to the growth and multiplication of phosphorus accumulating organisms (PAOs). The anaerobic environment of biological selector section can promote the phosphorus release. And phosphorus accumulating organisms in biological selector section can adsorb and absorb plenty of easily degradable organic matters, providing enough nutrition for the following aerobic phosphorus uptake. Thus, Effective phosphorus removal is achieved by controlling $\mathrm{DO}$ at $2-3 \mathrm{mg} / \mathrm{L}$ and ORP between $-150 \mathrm{mV}$ and $+100 \mathrm{mV}$ in aeration period (Zou B.H. \& Wang H.B.2012).

Small occupation area. There are no primary sedimentation tank and secondary sedimentation tank in CAST with concise process, equipments with smaller amounts and fewer kinds and easy operation(Zou B.H. \& Wang H.B.2012).

Strong anti-shock load capability. Anti-shock load capability will be improved through adjusting process parameters based on water quantity and quality of influent water in CAST process. Aeration period should be expanded to meet the discharge standard and operate economically when concentration of COD or ammonia nitrogen in the influent water is high. In addition, adsorption to pollutants in biological selector section, to a great extent, reduces the influence of fluctuation of influent water quality on the main reaction section (Zou B.H. \& Wang H.B.2012).

Saving energy and investment. Compared to the traditional wastewater treatment technology, CAST and UNITANK need less electric consumption. This is resulted from that water impeller with high power and energy consumption, agitator and reflux pump, promoted by traditional technology of $\mathrm{A}^{2} / \mathrm{O}$ and oxidation ditch are running non-stop. On the contrary, agitator and reflux pump of CAST and UNITANK with lower electric consumption are running intermittently. Compared to UNITANK with its complex equipments and higher requirements of automation, through comprehensively evaluation, CAST technology has a better effect of energy-saving(Chen W.R. \& Ye T.J. et al. 2013).

\section{CAST process features and advantages}

CAST process has achieved further study and improvement in application after entering China.

Aeration control. Aeration control to aerobic bio-treatment technology is the key point to ensure the effluent water quality, save energy and reduce consumption. So aeration control technology is upgrading continuously. Constant aeration control has numerous disadvantages and is seldom in use. The most popular DO control ( $\mathrm{DO}<0.5 \mathrm{mg} / \mathrm{L}$ for common anaerobic/anoxic zone, 2 3 mg/L for aeration control), is basically capable of meeting the requirements of nitrogen and phosphorus removal and energy-saving. In theory, ORP control is more accurate, but its selection of control mode and parameter setting has not yet been decided( Wang H.Z. \& Chen P. et al. 2008).

Technology coupling. Chemical treatment technology can be added, for instance, hydrolysis acidification tank is set before CAST reaction tank to increase the wastewater $\mathrm{BOD}_{5} / \mathrm{COD}$ ratio and further promote degrading reaction of microorganism to the organic pollutants(Lin Y.Z. \& Chen L.J., et al. 2008). Coupling catalyzed iron internal electrolysis with CAST technology will increase the sludge activity and further improve the removal ratio of COD, TN and TP(Zhou P.F. \& Yu Y.P. , et al. 2011).

Adding agitator. In order to improve the technology, independent anoxia agitating period is added to strengthen denitrification and anaerobic phosphorus release (Xu L.J.\& Wang S., et al. 2011). Independent agitating in main reaction section will effectively improve sludge content and further microorganism activity and amounts of microorganism for denitrification to strengthen the denitrification function in the whole system. Besides, it can also increase the effect of traditional CAST technology and lower the influence of low temperature on TN removal (Liu B.Y.\&,Yang D., et al. 2014) 


\section{Problems and measures}

Completion in theory.In the SBR technology operated, this one is the most effective in bioremoval of nitrogen and phosphorus. For few understanding about the complex survival competition and ecological balance among micro-bio groups in non-stable CAST system, theories are just analysis from technological process CAST theory and engineering design is mainly based on experience in lack of perfect and agreed design methods and theoretical foundation. Therefore, further study needs to be made（Zhou, A.L. \& Niu. Y. J. 2010 ,Xu J.\& Sun J.Y.2007 ） .

lower treatment in winter of north.Wastewater temperature in winter of northern China is commonly $6 \sim 10^{\circ} \mathrm{C}$. The low temperature leads to lower micro-bio activity and smaller amounts bring about great difficulty in wastewater treatment. To ensure wastewater treatment effect in winter, such measures can be taken like reducing sludge discharge, expanding aeration and lowering sludge load. Preheating system is added at blower to raise temperature in aeration period and water temperature in reaction tank. MLSS concentration is kept at $3500 \sim 5500 \mathrm{mg} / \mathrm{L}$ to ensure nitration not influenced by low temperature.

Waste activated sludge discharge.Supernatant around the sludge pump easily enters into the sludge pump. So sludge collection should be multi-point instead of single point. Pierced collection pipe helps to effectively collect sludge. The diameter of sludge discharge pipe should not be too small to prevent the block.

Excess air discharge of decant water.After the aeration period, much air is left in the aeration pipe. For higher water levels in precipitation period, air is left in aeration pipe with no way to enter the water because of water pressure. In decant period, lower water level air is continuous escaped from pottery aerator because water pressure is lower than pipe pressure. Later, bigger bubbles and severe fluid mud will influence the precipitation effect. Electric air release valve can be added at the precipitation pipe. Excess air can be given off when opening the electric air release valve after the main air inlet valve is closed. It should be closed when the precipitation pipe confirms to barometric pressure to ensure no residual air escaping in decant period and the good water quality (Wang Z.X. \& Yang S.W.,et al.2012).

\section{Conclusions}

With the development of the computer automatic control technology and bio-technology, CAST will be applied widely for its various aspects of advantages in future.

Many CAST wastewater treatment plants have been founded in China. Researchers can analyze advantages and disadvantages of various modes by the general yield coefficient of these CAST plants, to provide reference for designers.

When large amounts of waste water need to treat, CAST wastewater treatment process is not easy

to control. This moment, Complexity of technology should be fully considered.

In conclusion, CAST is advantageous in domestic wastewater treatment, particularly in small and medium wastewater treatment plants.

\section{Acknowledgements}

This work was financially supported by Colleges and universities in Hebei province science and technology research key project(zh201283), Science and technology project of Hebei Province(13273617), 2014 annual Students Research Fund of Northeast University at Qinhuangdao(61441,61445,61459,61460) .

Corresponding author: Guori Dong 


\section{References}

[1] Bao H.F. \& Li Y.W. et al.2009. Shi Jin-bin..CAST process in treating urban domestic sewage and Industrial effluent [B], Heilongjiang Science and Technology of Water Conservancy 37(6):5455. (in Chinese)

[2] Chen K.L. \& Zhan J.2004. Principle and Design of CAST process treating urban sewage[A]. Environmental Science and Technology 27(4):71-73. (in Chinese)

[3] Chen W.R. \& Ye T.J. et al. 2013. Several energy saving technology of application of sewage treatment process. Water \& Waste Water Engineering 39(Supplement):263-266. (in Chinese)

[4] Lin Y.Z. \& Chen L.J., et al. 2008. Summary of CAST process sewage disposal plant. ENVIRONMENTAL ENGINEERING 26(6):22-23(in Chinese)

[5] Liu B.Y.\&,Yang D., et al. 2014. Application of optimized CAST process to industrial wastewater treatment in northen china in winter. TECHNOLOGY OF WATER TREATMENT 40(3):94-97.

[6] Wang H.Z. \& Chen P. et al. 2008. Research on aeration control in CAST process., Water \& Waste Water Engineering 34(2):56-59. (in Chinese)

[7] Wang Z.X. \& Yang S.W.,et al.2012. Common problems of CAST and solving measures thereof. INDUSTRIAL WATER \& WASTEWATER 43(5):50-53. (in Chinese)

[8] Xu J.\& Sun J.Y.2007. Discussion on design of cyclic activated sludge process. Water \& Waste Water Engineering 33(2):34-38. (in Chinese)

[9] Xu L.J.\& Wang S., et al. 2011. Modified CAST Process with High Efficiency and Low Consumption for Nitrogen and Phosphorus Removal. CHINA WATER \&WASTEWATER 27(24):99102. (in Chinese)

[10] Zhang,L. \& Wang S.P., et al. 2010. Study on nitrogen removal performance in conventional mode of CAST process.Chinese Journal of Environmental Engineering 4(12):2683-2686(in Chinese)

[11] Zhou, A.L. \& Niu. Y. J. 2010 . A Review of CAST Process for Wastewater Treatment. Hebei Chemical Industry 33(1):52-53(in Chinese)

[12] Zhou P.F. \& Yu Y.P., et al. 2011. The Study on Strengthening Denitrification \& Pephosphorization of CAST process with Catalyzed Iron Inner Electrolysis. TECHNOLOGY OF WATER TREATMENT 37(11):96-99.(in Chinese)

[13] Zhou X.L. et al.2009. New SBR Technology of Biological wastewater Treatment and Their Applications. Journal of Shanghai University of Electric Power 25(3):232-236. (in Chinese)

[14] Zou B.H. \& Wang H.B.2012.Design Principle and optimized operation of CAST process. Industrial Technology (08):113-115. (in Chinese) 